\title{
Anti-Phospholipase $A_{2}$ Receptor Antibodies in Recurrent Membranous Nephropathy
}

\author{
Andrea Kattah, MD ${ }^{1,{ }^{*}}$, Rivka Ayalon, MD ${ }^{2,{ }^{*}}$, Laurence H. Beck Jr., MD, PhD ${ }^{2}$, Dana G. \\ Sandor, MD², Fernando G. Cosio, MD ${ }^{1}$, Manish J. Gandhi, MD ${ }^{3}$, Sanjeev Sethi, MD, PhD ${ }^{4}$, \\ Elizabeth C. Lorenz, MD ${ }^{1}$, David J. Salant, MD $^{2}$, and Fernando C. Fervenza, MD, PhD ${ }^{1}$ \\ ${ }^{1}$ Department of Nephrology and Hypertension, Mayo Clinic, Rochester, MN \\ ${ }^{2}$ Department of Medicine, Section of Nephrology, Boston University School of Medicine, Boston, \\ MA \\ ${ }^{3}$ Division of Transfusion Medicine, Rochester, MN \\ ${ }^{4}$ Department of Pathology, Mayo Clinic, Rochester, MN
}

\begin{abstract}
About $70 \%$ of patients with primary membranous nephropathy (MN) have circulating antiphospholipase $\mathrm{A}_{2}$ receptor $\left(\mathrm{PLA}_{2} \mathrm{R}\right)$ antibodies that correlate with disease activity, but their predictive value in post-transplant (Tx) recurrent $\mathrm{MN}$ is uncertain. We evaluated 26 patients, 18 with recurrent $\mathrm{MN}$ and 8 without recurrence, with serial post-Tx serum samples and renal biopsies to determine if patients with pre-Tx anti-PLA ${ }_{2} \mathrm{R}$ are at increased risk of recurrence as compared to seronegative patients and to determine if post-Tx changes in anti-PLA $\mathrm{A}_{2} \mathrm{R}$ correspond to the clinical course. In the recurrent group, 10/17 patients had anti-PLA 2 R at the time of Tx vs. 2/7 patients in the non-recurrent group. The positive predictive value of pre-Tx anti-PLA ${ }_{2} \mathrm{R}$ for recurrence was $83 \%$, while the negative predictive value was $42 \%$. Persistence or reappearance of post-Tx anti$\mathrm{PLA}_{2} \mathrm{R}$ was associated with increasing proteinuria and resistant disease in many cases; little or no proteinuria occurred in cases with pre-Tx anti-PLA $\mathrm{A}_{2} \mathrm{R}$ and biopsy evidence of recurrence in which the antibodies resolved with standard immunosuppression. Some cases with positive pre-Tx anti$\mathrm{PLA}_{2} \mathrm{R}$ were seronegative at the time of recurrence. In conclusion, patients with positive pre-Tx anti-PLA ${ }_{2} \mathrm{R}$ should be monitored closely for recurrent MN. Persistence or reappearance of antibody post-Tx may indicate a more resistant disease.
\end{abstract}

\section{Keywords}

Membranous nephropathy; recurrent disease; kidney transplant; M-type phospholipase $\mathrm{A}_{2}$ receptor

Corresponding Author: Fernando C. Fervenza, MD, PhD Mayo Clinic Division of Nephrology and Hypertension 200 First Street SW

Rochester, MN 55905, USA Phone: 507-266-1045 Fax: 507-266-7891 fervenza.fernando@ mayo.edu.

The first two authors contributed equally to this publication

Financial interests

LHB and DJS are co-inventors on the US patent, Diagnostics for Membranous Nephropathy. 


\section{Introduction}

Primary (idiopathic) membranous nephropathy (MN) is an organ-specific autoimmune disease caused by circulating autoantibodies that target glomerular podocyte antigens. The predominant target antigen is the M-type phospholipase $\mathrm{A}_{2}$ receptor $\left(\mathrm{PLA}_{2} \mathrm{R}\right)$ and anti$\mathrm{PLA}_{2} \mathrm{R}$ antibodies are found in the serum of $70 \%$ patients with active primary $\mathrm{MN}(1-6)$. Moreover, $\mathrm{PLA}_{2} \mathrm{R}$ is typically detected in the glomerular immune deposits of patients with primary $\mathrm{MN}$ by immunohistology where it can serve as a footprint of $\mathrm{PLA}_{2} \mathrm{R}$-associated $\mathrm{MN}$ even after patients have entered an immunological remission and serum anti-PLA ${ }_{2} \mathrm{R}$ is no longer detectable $(1,7-9)$.

About a third of patients with primary MN may develop end-stage renal disease (ESRD)(10, 11) and many are suitable candidates for kidney transplantation. Unfortunately, recurrence can occur in approximately $40 \%$ of patients, usually within the first year(12). Recurrent MN varies in severity from a subclinical finding apparent only on protocol kidney biopsy to a severe disease manifesting by heavy proteinuria and a high risk of allograft failure $(13,14)$. Case reports and small case series have shown that early identification of clinical recurrence and treatment with rituximab (RTX) can induce remission and avoid progressive kidney failure $(14,15)$. However there has been no way to predict which patients with end-stage $\mathrm{MN}$ will develop recurrent $\mathrm{MN}$ or to detect its early occurrence other than by protocol biopsies.

The primary purpose of this study was to determine if knowledge of a patient's anti-PLA ${ }_{2} \mathrm{R}$ status at the time of transplantation has utility in forecasting their risk of recurrent MN. If, as suggested by previous case studies, anti-PLA 2 R antibodies are able to transfer the disease to the transplanted kidney $(4,16,17)$, one would predict that those patients with persistently circulating antibodies at and after the time of transplantation would be at the greatest risk of recurrence. Given this theoretical risk, we set out to determine if $\mathrm{MN}$ recurs more frequently in patients that are seropositive for anti-PLA ${ }_{2} \mathrm{R}$ than in those that are seronegative at the time of transplantation. To do this we took advantage of a case series in which patients with end-stage primary $\mathrm{MN}$ were followed with serial post-Tx protocol biopsies and serum collections before and after Tx. The longitudinal nature of the study enabled us to follow the clinical and serological outcome of the cases with histological and clinical recurrence.

\section{Materials and Methods}

\section{Patient Population}

We identified 37 patients with ESRD who underwent kidney Tx at the Mayo Clinic due to primary MN between the years 2000-2010. We included all patients with available protocol biopsies, as well as at least one available stored serum sample in the Mayo Clinic Transplant Center Serum/Tissue Bank. Protocol biopsies were initiated at our institution in 1998 and occur at time of transplantation, 4, 12, 24 and 60 months post-Tx. We additionally attempted to retrieve native kidney biopsies from both Mayo Clinic and outside institutions. This study was conducted with the approval of the Mayo Clinic Institutional Review Board (IRB \# 09-004518). 
Biopsies

Recurrent MN was defined by the presence of positive IgG staining in a capillary loop pattern by immunofluorescence (IF) and subepithelial deposits on electron microscopy (EM) (18).

\section{Tx Immunosuppression}

The majority of patients with both recurrent and non-recurrent $\mathrm{MN}$ received thymoglobulin for induction (14/18 vs. 6/8, respectively). Two patients received thymoglobulin and RTX for induction, one for a positive cross-match [4] and one for an ABO-incompatible Tx [24]. The remaining patients received either basiliximab $[7,10,18]$ or daclizumab [25] for induction. The majority of patients (80\%) received tacrolimus, mycophenolate mofetil and steroids for maintenance immunosuppression.

\section{Anti-PLA $\mathbf{A}_{2} \mathrm{R}$ Western blotting and ELISA}

All available pre- and post-Tx serum samples were assayed both by Western blotting (WB) and with a commercial enzyme-linked immunosorbent assay (ELISA; Euroimmun US, Morris Plains, NJ).

For WB, extracts of human glomeruli (containing native $\mathrm{PLA}_{2} \mathrm{R}$ ) and recombinant human $\mathrm{PLA}_{2} \mathrm{R}\left(\mathrm{rPLA}_{2} \mathrm{R}\right)$ were electrophoresed and immunoblotted with patients' sera diluted at $1: 25$, as previously described(1). The anti-PLA ${ }_{2} \mathrm{R}$ level was semi-quantitated using a scale from 0 to 3 according to band intensity as compared to a well-characterized positive control. All weakly positive WB signals were repeated and confirmed as positive signals.

In cases where all samples from an individual patient were found to be negative for the $\operatorname{IgG} 4$ subclass of anti-PLA ${ }_{2} \mathrm{R}$, the pre-Tx sample was re-assayed for total $\operatorname{IgG}$ anti-PLA ${ }_{2} \mathrm{R}$ to detect the potential presence of other IgG subclasses. In the patients with positive tissue staining for $\mathrm{PLA}_{2} \mathrm{R}$ and negative serum anti-PLA $\mathrm{A}_{2} \mathrm{R}$ at the time of histologic recurrence with a previously positive serum anti-PLA ${ }_{2} \mathrm{R}$ (see below), the samples were repeated at dilution of $1: 10$ to increase sensitivity.

ELISA for anti-PLA ${ }_{2} \mathrm{R}$ was carried out according to the manufacturer's instructions. In brief, sera diluted to 1:100 were incubated 30 min with $P_{L A} R$ coated microplates (Euroimmun US) and detected by incubation with anti-human-IgG HRP conjugate that recognizes all human IgG subclasses. A highly positive index patient serum provided in the ELISA kit was used to generate a standard curve consisting of five calibrators $(2,20,100$, 500 , and 1500 relative units $[\mathrm{RU}] / \mathrm{ml})$. In addition, we included our well-characterized positive control with each ELISA plate.

\section{Tissue staining for $\mathrm{PLA}_{2} \mathrm{R}$}

We examined all available serial sections from formalin fixed paraffin blocks ( 3 micron). Sections were deparaffinized with xylene and treated with proteinase $\mathrm{K}(20 \mathrm{mg} / \mathrm{ml}, 15 \mathrm{~min}$ at $37^{\circ} \mathrm{C}$; Invitrogen) for antigen retrieval. Sections were incubated with rabbit polyclonal anti-PLA 2 R1 (1:100; Sigma/Atlas) for $30 \mathrm{~min}$. As we anticipated weak $\mathrm{PLA}_{2} \mathrm{R}$ staining in patients with early stages of recurrence or in patients with resolving $\mathrm{MN}$, amplification was 
used in all cases to optimize staining. The amplification process included sequential blocking with streptavidin and biotin (15 min; Streptavidin/Biotin blocking kit, Vector Laboratories) followed by biotinylated goat anti-rabbit IgG (1:200 for $45 \mathrm{~min}$; Vector Laboratories) and DyLight 488 Streptavidin (1:100 for $45 \mathrm{~min}$; Vector Laboratories).

All staining was done on coded sections without knowledge of the histological or clinical diagnosis and included a known positive control and known negative controls (lupus nephritis or normal human kidney). All glomeruli were photographed at 200x using an Olympus DP72 camera attached to a Nikon epifluorescence microscope. The coded images were scored as positive, negative, or equivocal by five observers, with high inter-observer agreement. Any images on which there was disagreement were reviewed together by all five observers to reach a consensus.

\section{HLA typing}

HLA typing of donors and recipients were reviewed and this data is provided in the supplement (Supplementary Table S1).

\section{IgG subtyping}

We performed IgG subtyping (IgG subclass 1-4) on a single post-Tx biopsy specimen in patients with recurrent disease at the time point closest to the time of initial recurrence, when available. Results shown in Supplementary Table S2.

\section{Results}

\section{Patient characteristics}

The data and samples for this study were from patients with primary MN that received a kidney Tx at the Mayo Clinic between 2000 and 2010. Of the 37 patients with idiopathic $\mathrm{MN}$ as their native renal disease, 21 had histologic recurrence post-Tx on protocol biopsy (57\%) and 16 had no evidence of recurrence. Eleven patients were excluded due to lack of consent $(n=10)$ or availability of serum $(n=1)$, and therefore our analysis is based on atal of 26 patients: 18 with recurrent MN and 8 without recurrence (Table 1).

The median time to recurrence, defined as a histologic recurrence regardless of level of proteinuria, was 4.1 months (IQR 2.6-38.5 months). The median proteinuria and mean serum creatinine at the time of recurrence was $533 \mathrm{mg} /$ day (IQR 253-1679 mg/day) and 1.80 $\pm 1.05 \mathrm{mg} / \mathrm{dl}$, respectively.

\section{Comparison of anti-PLA $\mathrm{A}_{2} \mathrm{R}$ Western blotting and ELISA}

Using the manufacturer's definition for anti-PLA ${ }_{2} \mathrm{R}$ negativity as $<14 \mathrm{RU} / \mathrm{ml}$, there was 92\% (160/174) concordance between WB and ELISA (Supplementary Table S3). Some have suggested that any titer above $2 \mathrm{RU} / \mathrm{ml}$ by the commercial ELISA may be considered positive (19). Using this definition, 10 of the 14 samples would be re-classified as seropositive. Due to the increased sensitivity of WB over ELISA, we have reported anti$\mathrm{PLA}_{2} \mathrm{R}$ seropositivity based on the WB signal rather than ELISA (see Supplement). 


\section{Predictive value of pre-Tx anti-PLA $2 R$}

Pre-Tx serum was available from 24 patients at a median of 2 days (range 1-7) prior to Tx. Seropositivity for anti-PLA ${ }_{2} \mathrm{R}$ is shown on a per-patient basis in Tables 2 and 3, along with tissue staining for $\mathrm{PLA}_{2} \mathrm{R}$ in the allograft, clinical features at time of recurrence and clinical course of the recurrent (1-18; Table 2) and non-recurrent (19-26; Table 3) patients. Median follow-up was 98 months (IQR 74-135) in non-recurrent patients and 88 months (IQR 64-122) in recurrent patients.

In those with recurrent MN, 17/18 had available pre-Tx samples of which 10/17 (59\%) were seropositive for anti-PLA $2 \mathrm{R}$ by Western blot. In the group of MN patients without recurrence, 7/8 had available pre-Tx serum samples, of which 2/7 (29\%) were seropositive for anti-PLA ${ }_{2} \mathrm{R}$. The association of pre-Tx anti-PLA ${ }_{2} \mathrm{R}$ reactivity with $\mathrm{MN}$ recurrence is illustrated in Figure 1. The positive predictive value (PPV) of pre-Tx anti-PLA ${ }_{2} \mathrm{R}$ for recurrence was $83 \%$. Patient 9 did not have a pre-Tx sample, but was seropositive for anti$\mathrm{PLA}_{2} \mathrm{R}$ two months after Tx with positive glomerular staining for $\mathrm{PLA}_{2} \mathrm{R}$. Of the 12 patients who were seronegative for anti-PLA ${ }_{2} \mathrm{R}$ pre-Tx, 5 have not recurred and 7 have recurred, which yields a negative predictive value (NPV) of $42 \%$.

\section{Tissue staining for $\mathrm{PLA}_{2} \mathrm{R}$}

A total of 59 follow-up biopsies on all recurrent and non-recurrent $\mathrm{MN}$ patients were available (2-3 follow-up biopsies per patient) for $\mathrm{PLA}_{2} \mathrm{R}$ staining (Table 4). Nine sections had no glomeruli or no tissue, and hence were not informative, leaving one recurrent patient [6] without tissue for $\mathrm{PLA}_{2} \mathrm{R}$ staining.

In the recurrent $\mathrm{MN}$ group, none of the patients consistently seronegative for anti-PLA ${ }_{2} \mathrm{R}$ pre- and post-Tx had positive tissue staining. Hence, the tissue staining did not reveal any additional cases of $\mathrm{PLA}_{2} \mathrm{R}$-associated $\mathrm{MN}$. In cases of known $\mathrm{PLA}_{2} \mathrm{R}$-associated $\mathrm{MN}$, all available sections at the time of recurrence stained positive for $P_{2} A_{2} R$. Four patients with $\mathrm{PLA}_{2} \mathrm{R}$-associated $\mathrm{MN}$ had positive tissue staining at the time of recurrence but were seronegative for anti-PLA $2 \mathrm{R}[11,13,14,18]$.

Only one patient [7] with known $\mathrm{PLA}_{2} \mathrm{R}$-associated recurrent $\mathrm{MN}$ and a biopsy showing 2+ $\mathrm{IgG}$ and trace $\mathrm{C} 3$ on IF exhibited negative PLA ${ }_{2} \mathrm{R}$ staining. In this case, EM showed stage 4 $\mathrm{MN}$, at which time the antigen may have been resorbed from the deposits.

In the non-recurrent group, none of the tissue sections were positive for $\mathrm{PLA}_{2} \mathrm{R}$.

We located13 native biopsies from both Mayo Clinic and outside institutions; however, only 7 had glomeruli for review. Five of these patients $[5,8,9,18,22]$ were positive for $\mathrm{PLA}_{2} \mathrm{R}$ and 2 were negative $[3,21]$ (Supplementary Table S2 and Table 3).

\section{Change in post-Tx anti-PLA $2 R$}

The post-Tx course of patients who were seropositive for anti-PLA ${ }_{2} R$ pre-Tx was variable. We will discuss selected cases with and without recurrent $\mathrm{MN}$ in the following sections and further case descriptions are in the supplement. Complete remission (CR) was defined as proteinuria $\leq 0.3 \mathrm{~g} / \mathrm{day}$ and partial remission $(\mathrm{PR})$ was defined as proteinuria $3.5 \mathrm{~g} / \mathrm{day}$ and a 
$>50 \%$ reduction from pretreatment levels of proteinuria. No response (NR) included a < $50 \%$ reduction, no change, or an increase in proteinuria.

\section{Positive pre-Tx anti-PLA $A_{2} R$ with recurrent MN}

Patient 11 was diagnosed with recurrent $\mathrm{MN}$ by biopsy with positive $\mathrm{PLA}_{2} \mathrm{R}$ staining 3 months post-Tx, at which point his anti-PLA ${ }_{2} \mathrm{R}$ antibody was already negative. His proteinuria increased from $0.5 \mathrm{~g} /$ day at the time of recurrence to $>1 \mathrm{~g} /$ day almost a year later while his anti-PLA ${ }_{2} \mathrm{R}$ antibody remained undetectable and a decision was made to treat with RTX (Figure 2). He responded well and eventually achieved a CR with improving biopsy features of $\mathrm{MN}$, including decreased staining for tissue $\mathrm{PLA}_{2} \mathrm{R}$.

Patient 15 exhibited histologic changes indicating very early recurrent $\mathrm{MN}$ at 2.5 months post-Tx. The next available serum sample at 13 months post-Tx showed disappearance of the antibodies without additional treatment other than the Tx immunosuppression. He had minimal proteinuria as well as a histologic resolution of recurrent $\mathrm{MN}$ by protocol biopsy in the setting of documented anti-PLA ${ }_{2} \mathrm{R}$ seronegativity four years post-Tx. However, his antibodies reappeared and in the fifth year post-Tx, he recurred with significant proteinuria and lost his graft within months and so was re-transplanted a few months later without receiving RTX. The antibodies were still detected at time of second Tx and he developed early histologic recurrence with minimal proteinuria (Figure 3).

Patient 5 was treated early with RTX for the simultaneous presence of recurrent MN and antibody-mediated rejection. The anti-PLA ${ }_{2} \mathrm{R}$ levels decreased but remained persistent at a low level, and ongoing MN was detected on subsequent biopsies with positive $\mathrm{PLA}_{2} \mathrm{R}$ staining. She ultimately reached ESRD, due to a combination of recurrent disease and chronic rejection (Figure 4).

Patient 8 had a high pre-Tx anti-PLA ${ }_{2} \mathrm{R}$ level that remained high at the time of recurrence, 3 months post-Tx. Due to increasing proteinuria, RTX was given at 10 months post-Tx. The antibodies decreased after the first RTX course but then increased with worsening proteinuria up to $>3 \mathrm{~g}$ /day and he was treated with a second course of RTX 3 years post-Tx, this time with achievement of a CR despite continued presence of the antibodies. Anti$\mathrm{PLA}_{2} \mathrm{R}$ eventually resolved 3 years after the second RTX dose. His proteinuria worsened a third time to $>3 \mathrm{~g}$ /day requiring a third RTX course. His protocol biopsies have shown features of ongoing $\mathrm{MN}$ on biopsy including positive $\mathrm{PLA}_{2} \mathrm{R}$ tissue staining (Figure 5).

\section{Positive pre-Tx anti-PLA $2 R$ without recurrent MN}

Two patients $[20,23]$ had strongly positive pre-Tx anti-PLA ${ }_{2} R$ but have not demonstrated evidence of recurrent $\mathrm{MN}$ on any protocol biopsies, starting at the 4-month point. However, in both cases, the first post-Tx serum sample was not available for anti-PLA ${ }_{2} R$ testing until 2 and 5 years later, respectively, and both were seronegative.

\section{Negative pre-Tx anti-PLA $2 R$ with and without recurrent MN}

All seven patients with recurrent $\mathrm{MN}$ and 5 with no recurrence who were seronegative for anti-PLA ${ }_{2} R$ pre-Tx remained seronegative during the post-Tx course. 


\section{Prior history of positive anti-PLA $A_{2} R$, negative pre-Tx with recurrent MN}

Patient 18 is unique in that this was his second Tx, as his first was lost due to venous thrombosis. Prior to his first Tx, he was anti-PLA ${ }_{2} \mathrm{R}$ seropositive, but during the short period between transplants, the antibody disappeared such that he was seronegative at the time of his second Tx. His 4-month protocol biopsy showed recurrent MN with positive PLA ${ }_{2} R$ tissue staining, although his serum remained negative for anti-PLA ${ }_{2} \mathrm{R}$ and he has not developed significant proteinuria.

\section{Discussion}

The primary outcome of this study to determine the predictive value of pre-Tx anti-PLA ${ }_{2} \mathrm{R}$ in recurrent $\mathrm{MN}$ is that recurrence occurs in a high proportion of patients with positive preTx antibody (83\%), but also that the risk of recurrence is as high as $58 \%$ in those that are seronegative pre-Tx (Figure 1). In our cohort, the PPV of positive pre-Tx anti-PLA ${ }_{2} \mathrm{R}$ for recurrent $\mathrm{MN}$ is $83 \%$ and the negative predictive value is $42 \%$. Though the number of patients is small, further analysis of follow up data allows us to make broader statements that will be of value in the future. Although a positive test for anti-PLA ${ }_{2} \mathrm{R}$ pre-Tx predicts early recurrence of $\mathrm{MN}$, in some cases this is a subclinical biopsy finding that may resolve with standard post-Tx immunosuppression. It has been previously established that symptomatic recurrence may lead to graft $\operatorname{loss}(12,13,21-23)$. In this study that was an infrequent outcome (3/18) because most cases of recurrence that were detected by protocol biopsy were effectively treated with RTX if they developed proteinuria (11/18). A particularly informative subset of patients was those that were seropositive pre-Tx and became seronegative without additional immunosuppression [14, 18, 20, 23]. In these cases, prospective serial measurements showing decline and disappearance of anti-PLA ${ }_{2} \mathrm{R}$ could be used clinically in place of biopsies to monitor for recurrent disease.

We propose that patients with primary $\mathrm{MN}$ may be separated into two distinct groups-those with $\mathrm{PLA}_{2} \mathrm{R}$-associated $\mathrm{MN}$ and those with non-PLA ${ }_{2} \mathrm{R}$-associated $\mathrm{MN}$. We define those with $\mathrm{PLA}_{2} \mathrm{R}$-associated $\mathrm{MN}$ in this study as patients with a positive serum anti-PLA ${ }_{2} \mathrm{R}$ either pre- or post-Tx and/or positive staining for $\mathrm{PLA}_{2} \mathrm{R}$ in kidney tissue in the native biopsy or at the time of recurrence. Patients with documented native or recurrent $\mathrm{MN}$ on biopsy with consistently negative serum and negative tissue staining are considered to have non-PLA ${ }_{2} \mathrm{R}$-associated MN. Those patients who were seronegative pre-Tx and had no evidence of recurrence or no tissue available for staining at time of recurrence could potentially fall into either group, only prior information on anti-PLA $A_{2} R$ or $P_{2} A_{2} R$ staining of the native kidney biopsy at the time of original diagnosis could have distinguished them. Due to the lack of serum and limited availability of tissue samples from the time when patients were initially diagnosed with $\mathrm{MN}$ in their native kidneys, the recurrence rate amongst those with $\mathrm{PLA}_{2} \mathrm{R}$ associated and non-PLA $\mathrm{A}_{2} \mathrm{R}$ associated MN cannot be determined in this cohort, although there was close concordance between the native kidney $\mathrm{PLA}_{2} \mathrm{R}$ positivity and pretransplant anti-PLA ${ }_{2} \mathrm{R}$ status in the few cases in which tissue was available. However, we were able to identify a single subject [22] whose native biopsy stained for $\mathrm{PLA}_{2} \mathrm{R}$ thus establishing the disease as $\mathrm{PLA}_{2} \mathrm{R}$-associated MN. The finding of 
seronegativity at transplantation suggests a lack of immunologic activity, and is likely the reason why this patient had no evidence of recurrence.

Our study includes 18 patients with recurrence: 12 of them with $\mathrm{PLA}_{2} \mathrm{R}$-associated MN (66\%), 4 with non-PLA ${ }_{2} \mathrm{R}$ associated $\mathrm{MN}(22 \%)$, and 2 with unknown status (11\%). This rate is compatible with the prevalence of anti-PLA ${ }_{2} \mathrm{R}$ in patients with primary $\mathrm{MN}$. The overall recurrence rate in our cohort $(57 \%)$ is higher than in previously published series $(30-42 \%)(13,24)$, but could be related to earlier histologic diagnosis with protocol biopsies, longer follow up of our cohort, and the high number of living related donor transplants in this cohort(25).

Our biopsy protocol also provided a unique opportunity to verify whether the IgG1 subclass is dominant and predates IgG4 deposition in glomeruli as suggested by Huang et al. in native biopsies(20). Of the 7 patients (regardless of $\mathrm{PLA}_{2} \mathrm{R}$ status) that had biopsies available for $\operatorname{IgG}$ subtyping at the first time histologic recurrence was noted ([5, 6, 11, 14, $15,16,17], 6 / 7$ had predominantly IgG4 staining in capillary walls (Supplementary Table S2). Similarly, IgG4 was the only or dominant subclass in most of the earliest biopsies of subjects with PLA ${ }_{2} \mathrm{R}$-associated MN $[5,6,9,11,14,15]$. A single case of known non$\mathrm{PLA}_{2} \mathrm{R}$-associated MN [16] had only IgG1 staining.

\section{Recurrent MN}

In patients with positive pre-Tx anti-PLA ${ }_{2} \mathrm{R}$, the antibody can disappear within 13 months or less after Tx, which may be due to standard post-Tx immunosuppression, additional RTX treatment, or unknown factors related to antigen exposure in the allograft.

Early recurrence that resolved spontaneously could have been missed in some cases prior to the first protocol biopsy. In addition, a few patients were seronegative at time of recurrence and had positive tissue staining for $\mathrm{PLA}_{2} \mathrm{R}[11,13,14,18]$. In two of them [11, 14] one might argue that their high pre-Tx antibody levels induced an early recurrence but were no longer detectable in the serum by the time of the first protocol biopsy. Such reasoning cannot apply to patient 13 who recurred after 26 months and whose 4-month protocol biopsy did not have evidence of MN. Nor does it explain why patient 18 developed $\mathrm{PLA}_{2} \mathrm{R}$ associated recurrent $\mathrm{MN}$ in his second allograft at a time when he was apparently seronegative and thus his kidney was never exposed to detectable anti-PLA ${ }_{2} R$. This finding of negative anti-PLA ${ }_{2} \mathrm{R}$ in the serum with positive tissue staining is consistent with prior studies (4) and may reflect very low levels of circulating antibodies that are consumed by the allograft and thus are undetectable by the most sensitive methods available. These low levels may be able to accumulate in the glomeruli over time and not only cause histological changes detectable by immunostaining but can also induce clinical recurrence and graft loss despite apparent seronegativity. These data also suggest that tissue staining for $\mathrm{PLA}_{2} \mathrm{R}$ may be a more sensitive modality for detecting early recurrence, though this method may be less useful in centers that do not perform protocol biopsies.

The persistence or reappearance of anti-PLA ${ }_{2} \mathrm{R}$ may herald a more aggressive disease. In six patients $[5,7,8,9,10,15]$, anti-PLA ${ }_{2} \mathrm{R}$ levels remained positive or re-appeared years after $\mathrm{Tx}$ and were accompanied by symptomatic disease with significant proteinuria. 
Another insight from this study is that about half of those patients that were seronegative pre-Tx and post-Tx went on to develop symptomatic recurrent MN. As up to $20 \%$ of patients with idiopathic MN may have non-PLA 2 R-associated disease, we would expect that some of the patients in our cohort also have MN associated with one or more distinct, and as yet unidentified, podocyte antigens. However, assuming that at least some of these seronegative cases did indeed have $\mathrm{PLA}_{2} \mathrm{R}$-associated $\mathrm{MN}$ in immunologic remission at the time of transplantation, this study provided an opportunity to determine if they reactivated when exposed to the new allograft. Notably, none of these cases became seropositive post$\mathrm{Tx}$, and none of those with available tissue had positive PLA $\mathrm{A}_{2} \mathrm{R}$ immunostaining. These results suggest that post-Tx anti-PLA ${ }_{2} \mathrm{R}$ testing is of little value in cases that are seronegative pre-Tx unless they are known (from prior serological studies or $\mathrm{PLA}_{2} \mathrm{R}$ staining of their native kidney) to have $\mathrm{PLA}_{2} \mathrm{R}$-associated MN.

\section{Non-recurrent MN}

There were two patients that were seropositive for anti-PLA ${ }_{2} \mathrm{R}$ pre-Tx that became seronegative post-Tx and had no evidence of recurrent MN on protocol biopsy, which suggests that the antibodies either failed to transfer the disease to the allograft or Tx immunosuppression rapidly induced suppression of anti-PLA ${ }_{2} \mathrm{R}$ production. In those patients seronegative for anti-PLA ${ }_{2} \mathrm{R}$ at the time of $\mathrm{Tx}$, a proportion were likely cases of $\mathrm{PLA}_{2} \mathrm{R}$-associated who were immunologically inactive, such as patient 22 who was positive for the $\mathrm{PLA}_{2} \mathrm{R}$ antigen on native biopsy but seronegative at the time of Tx. While in antiglomerular basement membrane (GBM) disease, the recurrence rate is significantly reduced if circulating anti-GBM antibody levels have been undetectable for at least 12 months before $\operatorname{Tx}(26)$, the optimal duration of seronegativity in $\mathrm{PLA}_{2} \mathrm{R}$-associated $\mathrm{MN}$ is unknown.

Our findings are consistent with the findings of Debiec et al, who have previously shown that the kinetics of anti-PLA ${ }_{2} \mathrm{R}$ post-Tx is quite variable and we found similar patterns of change anti-PLA $A_{2} \mathrm{R}$ post-Tx(4). Our study has the advantage of using protocol biopsies, allowing us to identify subclinical, histologic recurrence of $\mathrm{MN}$, as well as more complete serologic follow up of anti-PLA $2 \mathrm{R}$, including both pre- and post-Tx samples.

Our study has several limitations. It is a small, retrospective study and so our analysis is limited by the availability of serum and tissue samples. The data is quite heterogeneous and our power to detect significant differences between groups is limited. In addition, we are unable to comment on the overall recurrence rate in $\mathrm{PLA}_{2} \mathrm{R}$-associated vs. non-PLA $\mathrm{A}_{2} \mathrm{R}$ associated $\mathrm{MN}$ due to limited native kidney biopsy specimens.

In conclusion, pre-Tx anti-PLA ${ }_{2} \mathrm{R}$ testing may have clinical utility either in those with known $\mathrm{PLA}_{2} \mathrm{R}$-associated disease or those who are seropositive at the time of transplant. Now that the assays are more widely available in the clinical setting, anti-PLA ${ }_{2} \mathrm{R}$ should be checked in all patients with primary $\mathrm{MN}$ being considered for transplantation and the native kidney biopsy should be stained for $\mathrm{PLA}_{2} \mathrm{R}$ in order to classify them as having $\mathrm{PLA}_{2} \mathrm{R}$ - or non-PLA 2 R-associated MN prior to transplantation. The presence of anti-PLA $A_{2} R$ at the time of Tx very often leads to early recurrence of MN. Induction therapy and standard maintenance immunosuppression in some cases are sufficient to induce immunologic remission, but do not preclude the possibility of recurrence of $\mathrm{PLA}_{2} \mathrm{R}$-associated MN. In 
those cases with persistence or reappearance of the antibody post-Tx the disease appears more resistant. The response to RTX is excellent and should be considered to prevent allograft loss.

Our study raises two practical issues. One is whether to postpone Tx until the circulating anti-PLA ${ }_{2} \mathrm{R}$ disappears and for how long to wait with an undetectable level before Tx? Second, considering the high recurrence rate documented in patients seropositive for anti$\mathrm{PLA}_{2} \mathrm{R}$ at the time of transplantation, should RTX be given preventively to all patients with either pre- or post-Tx anti-PLA ${ }_{2} \mathrm{R}$ seropositivity? Future prospective studies are needed to establish the answers to these questions.

\section{Supplementary Material}

Refer to Web version on PubMed Central for supplementary material.

\section{Acknowledgments}

We would like to thank Dr. Joel Henderson from the Department of Pathology and Laboratory Medicine at Boston University Medical Center for guidance and advice with the tissue staining.

This work is supported by R01 DK090029 (DJS, LHB), R01 DK 097053 (LHB) from NIH/NIDDK and NEPTUNE, Nephrotic Syndrome Study Network, U-54-DK-083912 (RA).

\section{Abbreviations}

$\begin{array}{ll}\text { MN } & \text { Membranous nephropathy } \\ \text { PLA } 2_{2} \text { R } & \text { M-type phospholipase } \mathrm{A}_{2} \text { receptor } \\ \text { ESRD } & \text { End-stage renal disease } \\ \text { RTX } & \text { Rituximab } \\ \text { Tx } & \text { Transplant } \\ \text { CR } & \text { Complete remission } \\ \text { PR } & \text { Partial remission } \\ \text { NR } & \text { No response } \\ \text { SNP } & \text { Single nucleotide polymorphism } \\ \text { PPV } & \text { Positive predictive value } \\ \text { NPV } & \text { Negative predictive value }\end{array}$

\section{References}

1. Beck LH Jr, Bonegio RG, Lambeau G, Beck DM, Powell DW, Cummins TD, et al. M-type phospholipase A2 receptor as target antigen in idiopathic membranous nephropathy. N Engl J Med. 2009 Jul 2; 361(1):11-21. Research Support, N.I.H., Extramural Research Support, Non-U.S. Gov't Research Support, U.S. Gov't, Non-P.H.S. [PubMed: 19571279]

2. Hofstra JM, Beck LH Jr, Beck DM, Wetzels JF, Salant DJ. Anti-phospholipase A(2) receptor antibodies correlate with clinical status in idiopathic membranous nephropathy. Clin J Am Soc 
Nephrol. 2011 Jun; 6(6):1286-91. Research Support, N.I.H., Extramural Research Support, NonU.S. Gov't. [PubMed: 21474589]

3. Hoxha E, Harendza S, Zahner G, Panzer U, Steinmetz O, Fechner K, et al. An immunofluorescence test for phospholipase-A(2)-receptor antibodies and its clinical usefulness in patients with membranous glomerulonephritis. Nephrol Dial Transplant. 2011 Aug; 26(8):2526-32. Comparative Study Research Support, Non-U.S. Gov't. [PubMed: 21633097]

4. Debiec H, Martin L, Jouanneau C, Dautin G, Mesnard L, Rondeau E, et al. Autoantibodies specific for the phospholipase A2 receptor in recurrent and De Novo membranous nephropathy. Am J Transplant. 2011 Oct; 11(10):2144-52. Research Support, Non-U.S. Gov't. [PubMed: 21827616]

5. Qin W, Beck LH Jr, Zeng C, Chen Z, Li S, Zuo K, et al. Anti-phospholipase A2 receptor antibody in membranous nephropathy. J Am Soc Nephrol. 2011 Jun; 22(6):1137-43. Research Support, N.I.H., Extramural. [PubMed: 21566055]

6. Oh YJ, Yang SH, Kim DK, Kang SW, Kim YS. Autoantibodies against phospholipase A2 receptor in Korean patients with membranous nephropathy. PLoS One. 2013; 8(4):e62151. Research Support, Non-U.S. Gov't. [PubMed: 23637987]

7. Svobodova B, Honsova E, Ronco P, Tesar V, Debiec H. Kidney biopsy is a sensitive tool for retrospective diagnosis of PLA2R-related membranous nephropathy. Nephrol Dial Transplant. 2013 Jul; 28(7):1839-44. Research Support, Non-U.S. Gov't. [PubMed: 23223223]

8. Debiec H, Ronco P. PLA2R autoantibodies and PLA2R glomerular deposits in membranous nephropathy. N Engl J Med. 2011 Feb 17; 364(7):689-90. Letter Research Support, Non-U.S. Gov't. [PubMed: 21323563]

9. Larsen CP, Messias NC, Silva FG, Messias E, Walker PD. Determination of primary versus secondary membranous glomerulopathy utilizing phospholipase A2 receptor staining in renal biopsies. Mod Pathol. 2013 May; 26(5):709-15. [PubMed: 23196797]

10. Donadio JV Jr, Torres VE, Velosa JA, Wagoner RD, Holley KE, Okamura M, et al. Idiopathic membranous nephropathy: the natural history of untreated patients. Kidney Int. 1988 Mar; 33(3): 708-15. [PubMed: 3367560]

11. Schieppati A, Mosconi L, Perna A, Mecca G, Bertani T, Garattini S, et al. Prognosis of untreated patients with idiopathic membranous nephropathy. N Engl J Med. 1993 Jul 8; 329(2):85-9. [PubMed: 8510707]

12. Dabade TS, Grande JP, Norby SM, Fervenza FC, Cosio FG. Recurrent idiopathic membranous nephropathy after kidney transplantation: a surveillance biopsy study. Am J Transplant. 2008 Jun; 8(6):1318-22. Research Support, Non-U.S. Gov't. [PubMed: 18444918]

13. Poduval RD, Josephson MA, Javaid B. Treatment of de novo and recurrent membranous nephropathy in renal transplant patients. Semin Nephrol. 2003 Jul; 23(4):392-9. Review. [PubMed: 12923728]

14. El-Zoghby ZM, Grande JP, Fraile MG, Norby SM, Fervenza FC, Cosio FG. Recurrent idiopathic membranous nephropathy: early diagnosis by protocol biopsies and treatment with anti-CD20 monoclonal antibodies. Am J Transplant. 2009 Dec; 9(12):2800-7. [PubMed: 19845581]

15. Sprangers B, Lefkowitz GI, Cohen SD, Stokes MB, Valeri A, Appel GB, et al. Beneficial effect of rituximab in the treatment of recurrent idiopathic membranous nephropathy after kidney transplantation. Clin J Am Soc Nephrol. 2010 May; 5(5):790-7. Research Support, Non-U.S. Gov't. [PubMed: 20185599]

16. Stahl R, Hoxha E, Fechner K. PLA2R autoantibodies and recurrent membranous nephropathy after transplantation. N Engl J Med. 2010 Jul 29; 363(5):496-8. Case Reports Letter Research Support, Non-U.S. Gov't. [PubMed: 20818871]

17. Seitz-Polski B, Payre C, Ambrosetti D, Albano L, Cassuto-Viguier E, Berguignat M, et al. Prediction of membranous nephropathy recurrence after transplantation by monitoring of antiPLA2R1 (M-type phospholipase A2 receptor) autoantibodies: a case series of 15 patients. Nephrol Dial Transplant. 2014 Jul 25.

18. Rodriguez EF, Cosio FG, Nasr SH, Sethi S, Fidler ME, Stegall MD, et al. The pathology and clinical features of early recurrent membranous glomerulonephritis. Am J Transplant. 2012 Apr; 12(4):1029-38. [PubMed: 22233329] 
19. Timmermans SA, Damoiseaux JG, Heerings-Rewinkel PT, Ayalon R, Beck LH Jr, Schlumberger W, et al. Evaluation of Anti-PLA2R1 as Measured by a Novel ELISA in Patients With Idiopathic Membranous Nephropathy: A Cohort Study. American Journal of Clinical Pathology. 2014 Jul; 142(1):29-34. [PubMed: 24926082]

20. Huang CC, Lehman A, Albawardi A, Satoskar A, Brodsky S, Nadasdy G, et al. IgG subclass staining in renal biopsies with membranous glomerulonephritis indicates subclass switch during disease progression. Mod Pathol. 2013 Jun; 26(6):799-805. [PubMed: 23328976]

21. Briganti EM, Russ GR, McNeil JJ, Atkins RC, Chadban SJ. Risk of renal allograft loss from recurrent glomerulonephritis. N Engl J Med. 2002 Jul 11; 347(2):103-9. Comparative Study. [PubMed: 12110738]

22. Cosyns JP, Couchoud C, Pouteil-Noble C, Squifflet JP, Pirson Y. Recurrence of membranous nephropathy after renal transplantation: probability, outcome and risk factors. Clin Nephrol. 1998 Sep; 50(3):144-53. Case Reports Review. [PubMed: 9776417]

23. Monga G, Mazzucco G, Basolo B, Quaranta S, Motta M, Segoloni G, et al. Membranous glomerulonephritis (MGN) in transplanted kidneys: morphologic investigation on 256 renal allografts. Mod Pathol. 1993 May; 6(3):249-58. Comparative Study Research Support, Non-U.S. Gov't. [PubMed: 8346172]

24. El-Zoghby ZM, Stegall MD, Lager DJ, Kremers WK, Amer H, Gloor JM, et al. Identifying specific causes of kidney allograft loss. Am J Transplant. 2009 Mar; 9(3):527-35. Research Support, Non-U.S. Gov't. [PubMed: 19191769]

25. Andresdottir MB, Wetzels JF. Increased risk of recurrence of membranous nephropathy after related donor kidney transplantation. Am J Transplant. 2012 Jan; 12(1):265-6. Letter. [PubMed: 22050629]

26. Netzer KO, Merkel F, Weber M. Goodpasture syndrome and end-stage renal failure--to transplant or not to transplant? Nephrol Dial Transplant. 1998 Jun; 13(6):1346-8. Editorial Review. [PubMed: 9641155] 


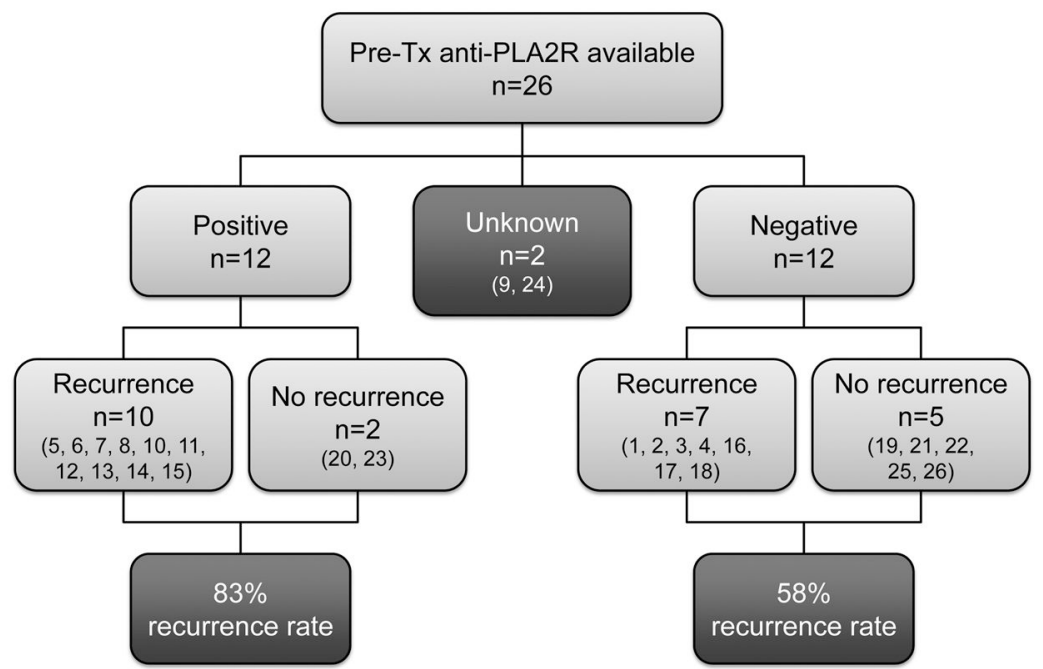

Figure 1.

Distribution of pre-Tx anti-PLA ${ }_{2} \mathrm{R}$ in those with and without MN recurrence (numbers according to Table $2 / 3$ ). 

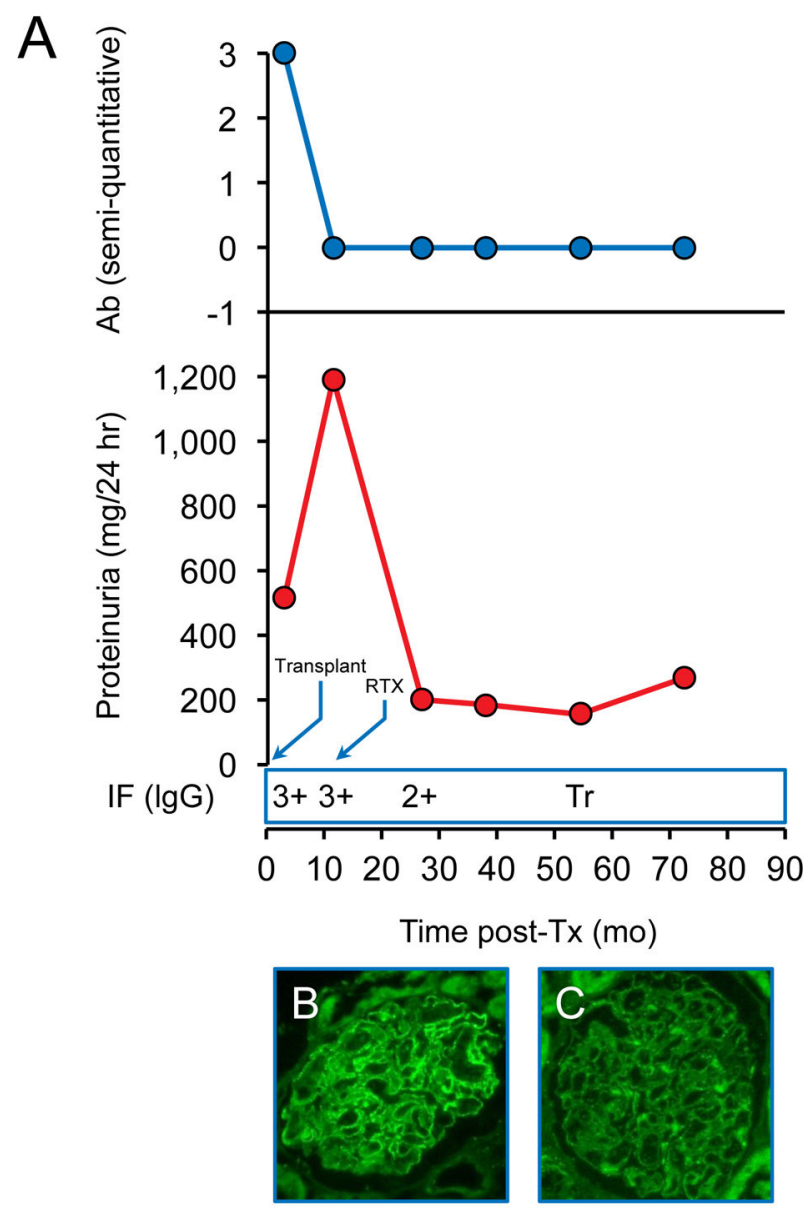

Figure 2.

Patient 11. Recurrence diagosed at 3 months post-Tx. A - Changes in proteinuria, semiquantitative $\mathrm{Ab}$ levels and IgG staining by immunofluorescence (IF) over time. ( $\mathrm{Tr}=$ trace). $\mathrm{B}-\mathrm{Positive} \mathrm{PLA}_{2} \mathrm{R}$ staining at 3 months post-Tx. C- Weakly positive PLA $2 \mathrm{R}$ staining 40 months after treatment with RTX. 


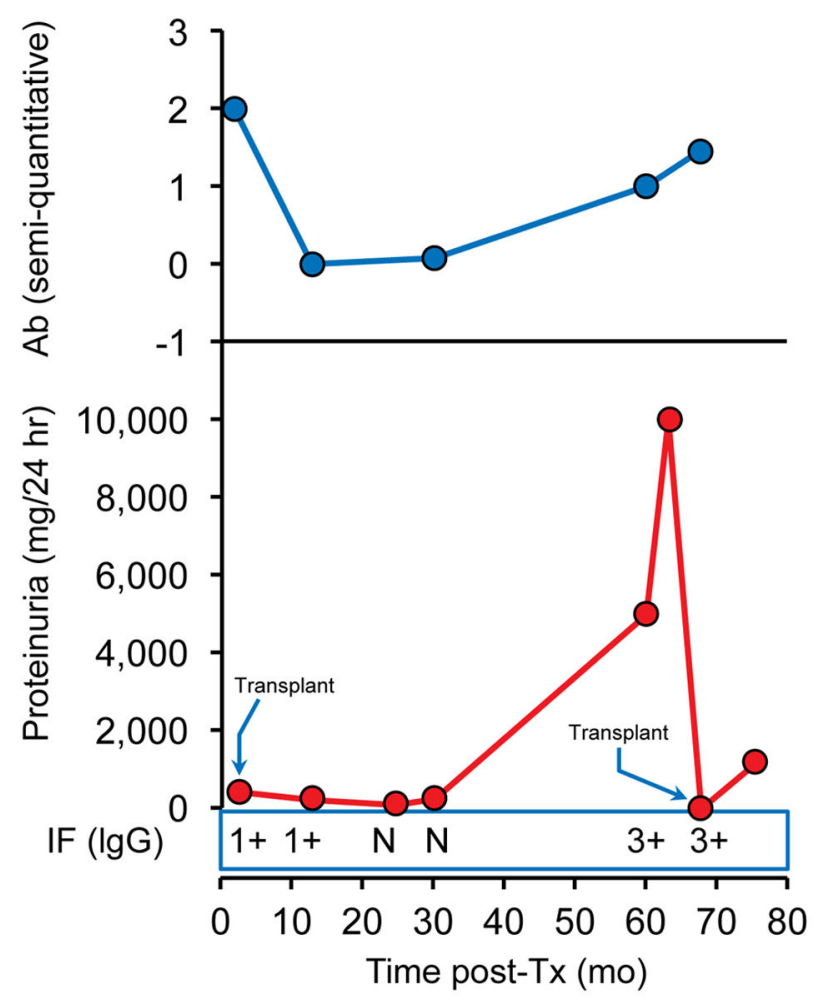

Figure 3.

Patient 15. Recurrence diagnosed 2.5 months post-first Tx and 5 months post-second Tx. Changes in proteinuria, semi-quantitative Ab levels and IgG staining by immunofluorescence (IF) over time. ( $\mathrm{N}=$ negative). Tissue for $\mathrm{PLA}_{2} \mathrm{R}$ staining was not available. 


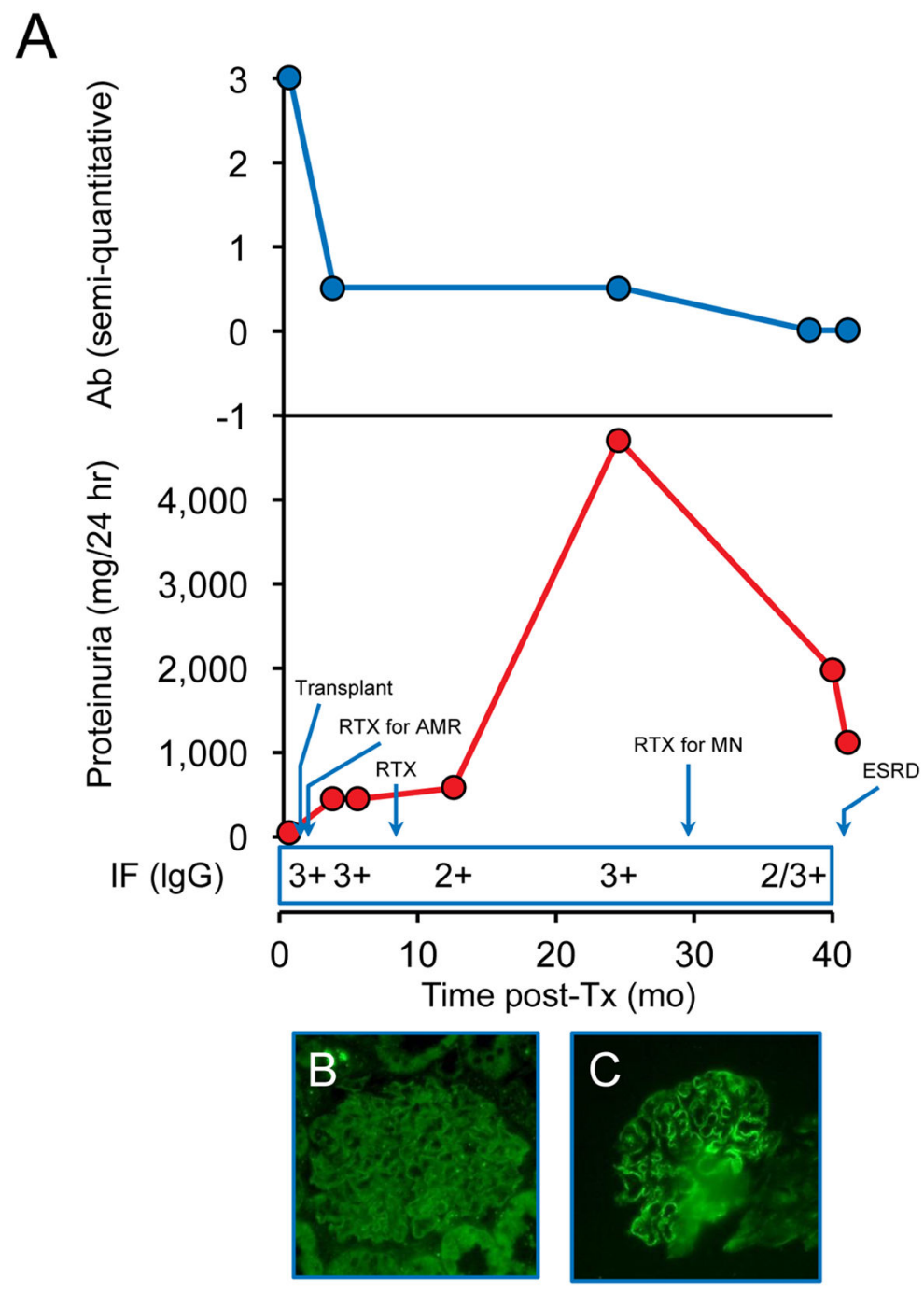

Figure 4.

Patient 5. Recurrence diagnosed at 0.3 months post-Tx. A- Changes in proteinuria, semiquantitative Ab levels and IgG staining by immunofluorescence (IF) over time. B- Weaklypositive $\mathrm{PLA}_{2} \mathrm{R}$ staining at 0.3 months post-Tx in setting of antibody-mediated rejection. CPositive PLA 2 R staining at 18 months post-Tx. 

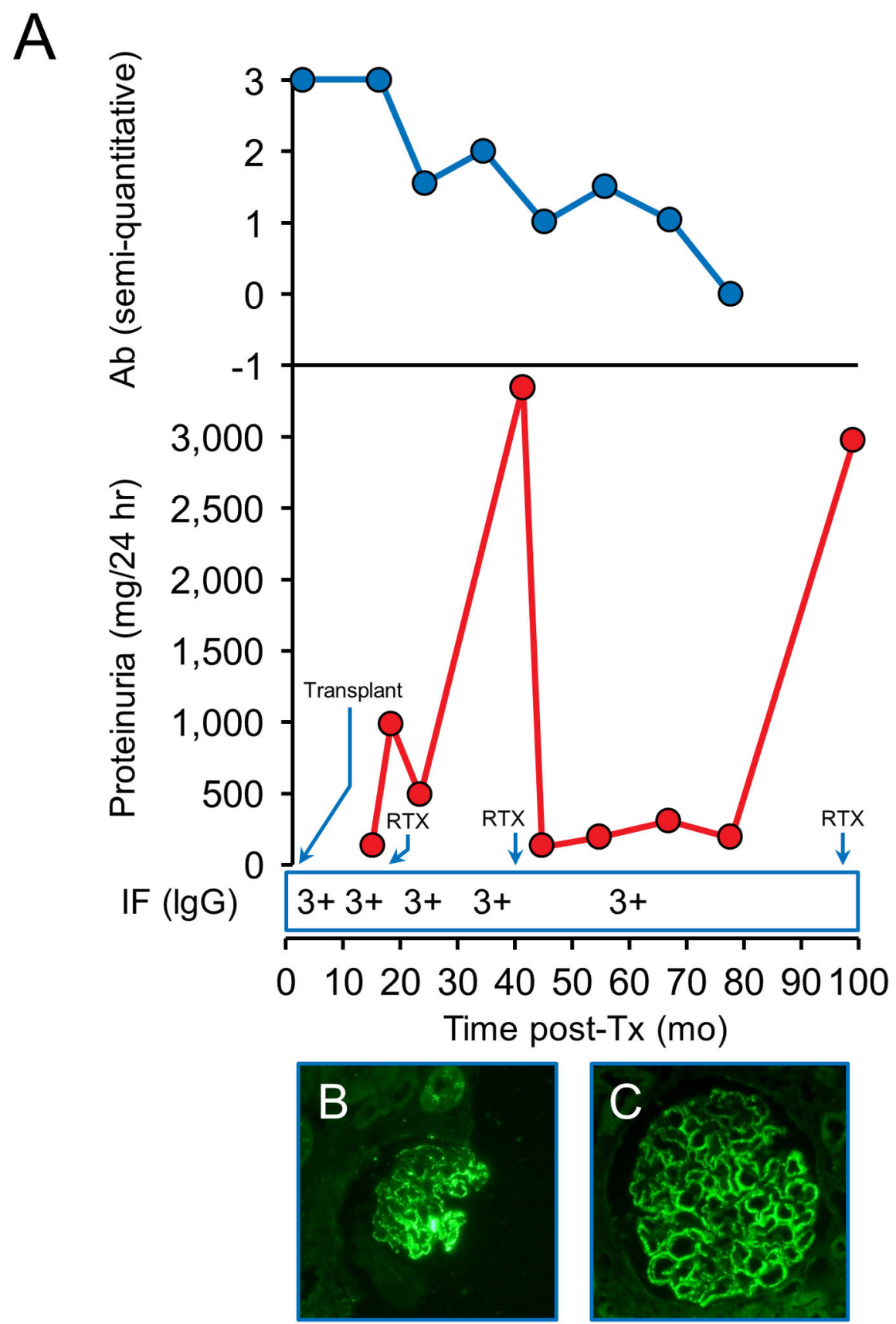

Figure 5.

Patient 8. Recurrence diagnosed at 4 months post-Tx. A - Changes in proteinuria, semiquantitative Ab levels and IgG staining by immunofluorescence (IF) over time. B-Positive $\mathrm{PLA}_{2} \mathrm{R}$ staining at 16 months post-Tx, after RTX. C- Positive PLA 2 R staining 5 years postTx, after two courses of RTX. 


\section{Table 1}

\section{Patient Characteristics}

\begin{tabular}{|c|c|c|c|}
\hline Characteristics & $\underline{\text { Non- recurrent } n=8}$ & Recurrent $n=18$ & P-value ${ }^{*}$ \\
\hline Age at initial diagnosis & $41.5 \pm 11.3$ & $41.7 \pm 13.6$ & 0.87 \\
\hline Age at transplant & $52.5 \pm 10.5$ & $51.3 \pm 11.1$ & 0.80 \\
\hline Sex (no, \% male) & $6(75 \%)$ & $11(61 \%)$ & 0.67 \\
\hline Race (no, \% Caucasian) & $8(100 \%)$ & $15(83 \%)$ & 0.53 \\
\hline \multicolumn{4}{|l|}{ Donor type (no, \%) } \\
\hline Living Related Donor & $3(37.5 \%)$ & $10(56 \%)$ & 0.135 \\
\hline Living Unrelated Donor & $1(12.5 \%)$ & $6(33 \%)$ & \\
\hline Cadaveric Donor & $4(50 \%)$ & $2(11 \%)$ & \\
\hline Biopsy-proven $\mathrm{MN}$ in native kidney (no, \%) & $8(100 \%)$ & $16(89 \%)$ & 1.0 \\
\hline Prior transplants (no, \%) & 0 & $4(22 \%)$ & 0.28 \\
\hline Standard triple immunosuppressant therapy (no, \%) & $6(75 \%)$ & $15(83 \%)$ & 0.63 \\
\hline Induction with Thymoglobulin (no, \%) & $6(75 \%)$ & $14(77 \%)$ & 1.0 \\
\hline
\end{tabular}

- Mean \pm standard deviation unless otherwise indicated

* Comparisons in baseline characteristics were performed by unpaired t-test, two tailed U test (Mann-Whitney) or Wilcoxon signed-rank test for continuous variables and Fisher's exact test for binary variables. 


\begin{tabular}{|c|c|c|c|c|c|c|c|c|c|c|c|c|c|c|}
\hline & 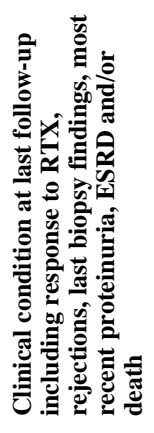 & 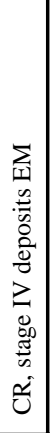 & 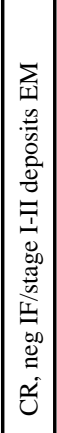 & 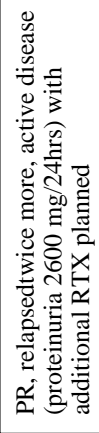 & 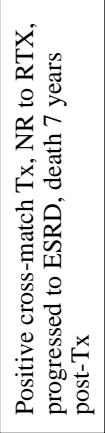 & 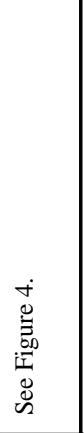 & 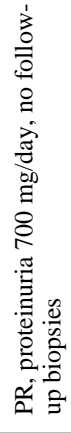 & 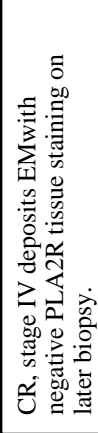 & 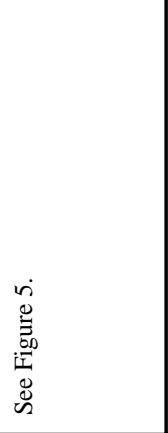 & 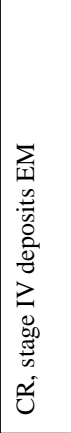 & 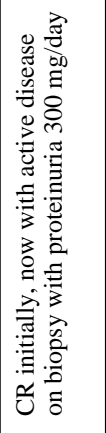 & 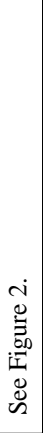 & 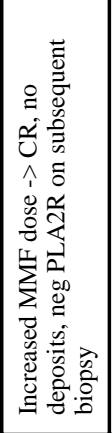 & 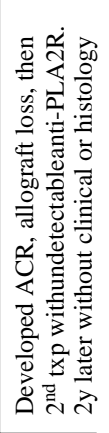 \\
\hline & 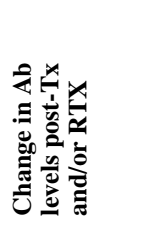 & 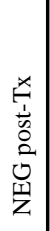 & 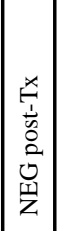 & 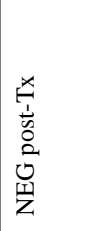 & 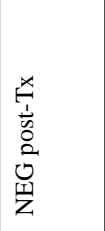 & 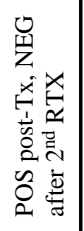 & 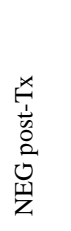 & 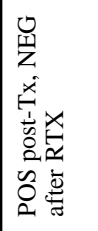 & 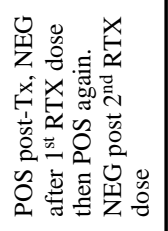 & 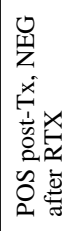 & 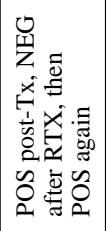 & 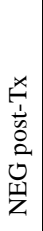 & 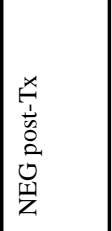 & 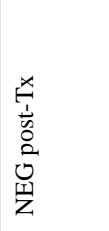 \\
\hline & 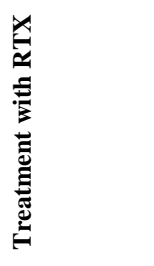 & $\stackrel{\infty}{\beth}$ & 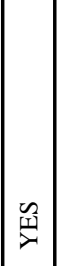 & \begin{tabular}{|l}
$\underbrace{2}$ \\
$\underline{\lambda}$
\end{tabular} & 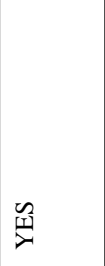 & 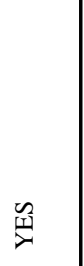 & 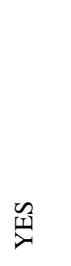 & 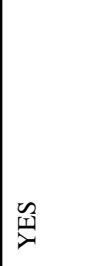 & 走 & 亗 & 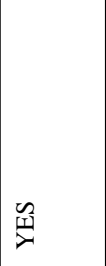 & $\stackrel{2}{ \pm}$ & そ & $\stackrel{\circ}{\gtrless}$ \\
\hline & 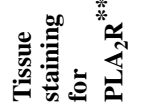 & $\begin{array}{l}0 \\
\text { 甲 } \\
z\end{array}$ & \begin{tabular}{|l}
0 \\
罗
\end{tabular} & 邑 & 邑 & 战 & $\overleftrightarrow{z}$ & $\mathbb{z}$ & $\stackrel{0}{0}$ & $\stackrel{0}{0}$ & ڤి & $\tilde{0}$ & 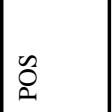 & $\tilde{2}$ \\
\hline & $\gtrless$ & $\begin{array}{l}0 \\
\text { 岁 }\end{array}$ & $\begin{array}{l}0 \\
\text { 崱 }\end{array}$ & $\begin{array}{l}0 \\
\text { 罗 }\end{array}$ & 号 & 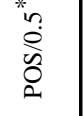 & \begin{tabular}{|l} 
巻 \\
堊
\end{tabular} & $\begin{array}{l}\mathbb{N} \\
\text { D } \\
0\end{array}$ & $\frac{m}{\tilde{\nu}}$ & $\begin{array}{l}\frac{1}{v} \\
0 \\
\Omega\end{array}$ & $\begin{array}{l}n \\
2 \\
\infty \\
0 \\
2\end{array}$ & $\begin{array}{l}0 \\
\text { 罗 }\end{array}$ & ${ }_{\overleftarrow{z}}^{w}$ & 号 \\
\hline 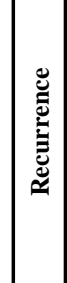 & 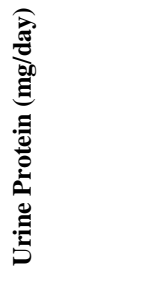 & $\frac{v}{d}$ & $\approx$ & ते & $\stackrel{\infty}{\stackrel{\infty}{\Xi}}$ & $\stackrel{\bar{\sim}}{\vec{v}}$ & बे & হু & $\stackrel{\infty}{ \pm}$ & તેे & ¿̊. & 范 & 寺 & 令 \\
\hline & $\begin{array}{l}\widehat{0} \\
\stackrel{\Xi}{\Xi} \\
\tilde{\Xi} \\
:\end{array}$ & $\because$ & $\infty$ & 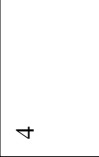 & $m$ & 3 & 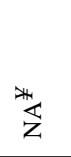 & n & $m$ & in & $n$ & $m$ & 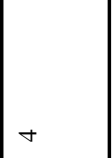 & $\stackrel{\sim}{\sim}$ \\
\hline & 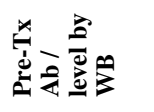 & $\begin{array}{l}0 \\
\text { 罗 }\end{array}$ & 吕 & $\begin{array}{l}0 \\
\text { 罗 }\end{array}$ & $\begin{array}{l}0 \\
口\end{array}$ & $\begin{array}{l}\frac{m}{\tilde{\omega}} \\
0 \\
\Omega\end{array}$ & $\begin{array}{l}\frac{1}{\tilde{y}} \\
0 \\
\alpha\end{array}$ & $\begin{array}{l}\frac{1}{\tilde{V}} \\
0 \\
\Omega\end{array}$ & $\begin{array}{l}\frac{m}{\tilde{n}} \\
0\end{array}$ & $\overleftrightarrow{z}$ & 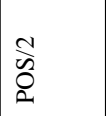 & 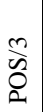 & $\begin{array}{l}\tilde{m} \\
\tilde{\delta} \\
0\end{array}$ & $\begin{array}{l}\frac{1}{\tilde{v}} \\
0 \\
\&\end{array}$ \\
\hline & 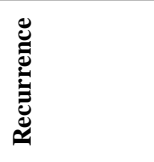 & $\succ$ & $\lambda$ & $\succ$ & $\lambda$ & $\lambda$ & $\succ$ & $\lambda$ & $\lambda$ & $\lambda$ & $>$ & $\lambda$ & $\lambda$ & $\succ$ \\
\hline & 离 & - & $\mathrm{N}$ & $m$ & 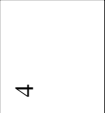 & in & 6 & $r$ & $\infty$ & $a$ & $\stackrel{\circ}{\circ}$ & $=$ & $\simeq$ & 9 \\
\hline
\end{tabular}

Am J Transplant. Author manuscript; available in PMC 2015 June 18. 


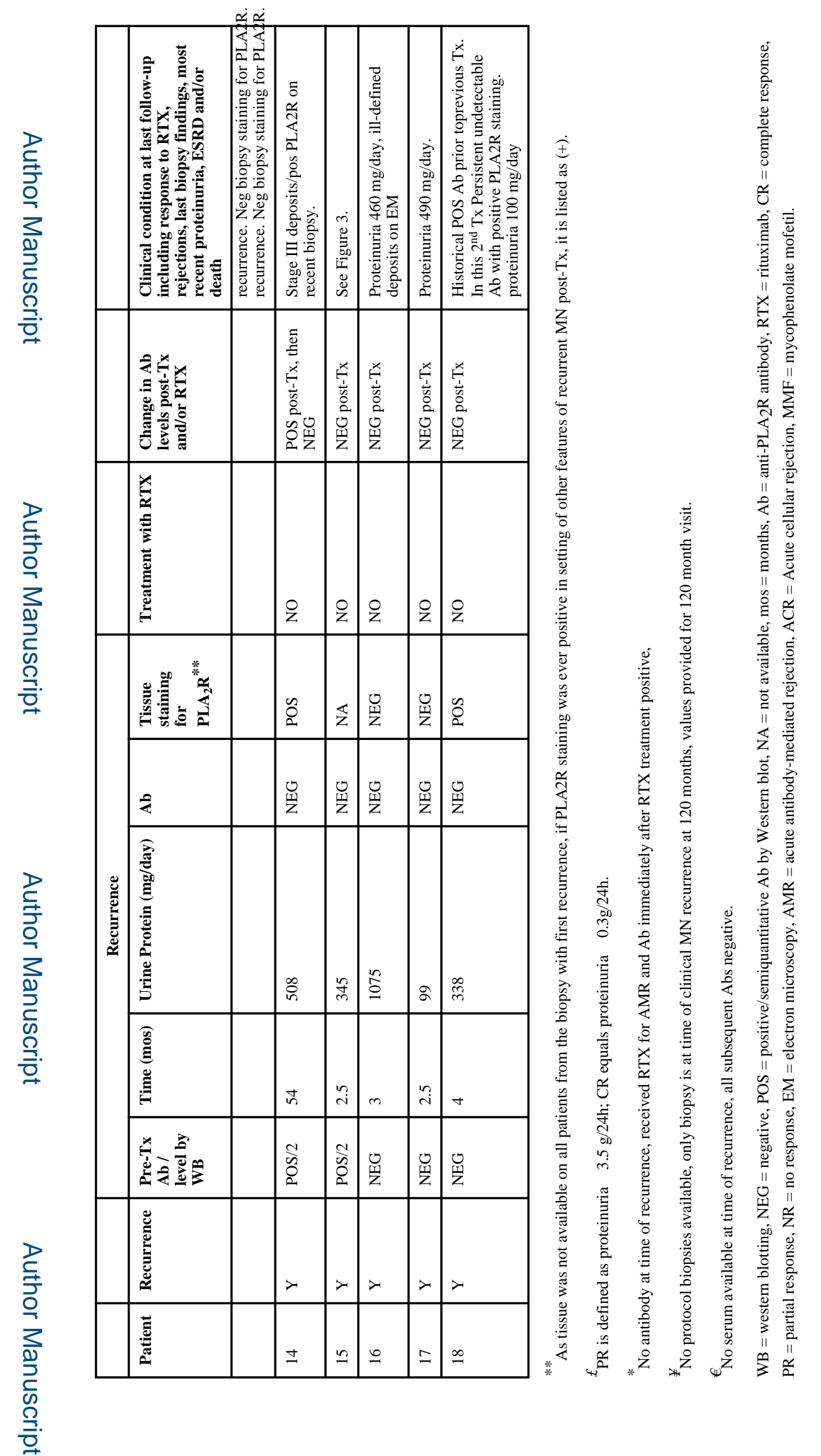

Am J Transplant. Author manuscript; available in PMC 2015 June 18. 


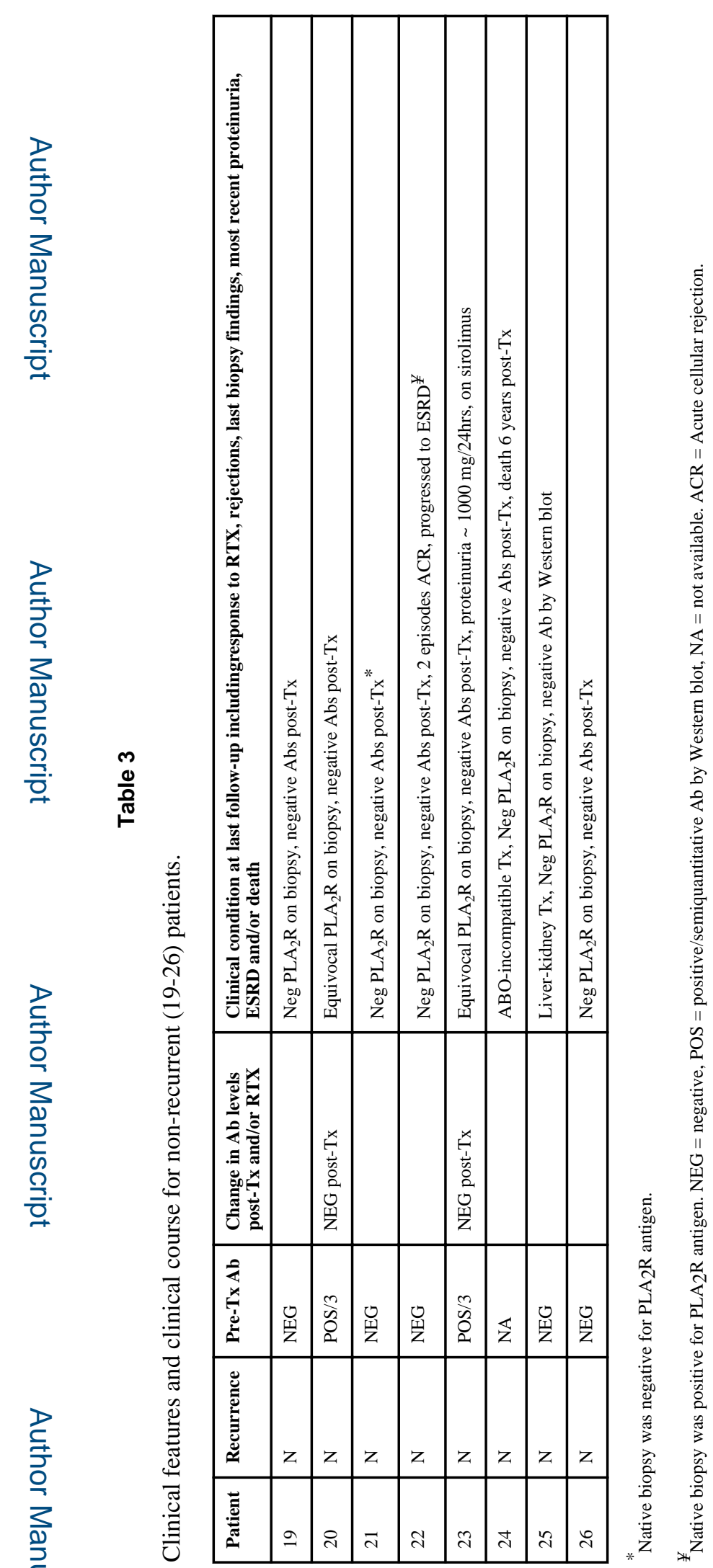

Am J Transplant. Author manuscript; available in PMC 2015 June 18. 


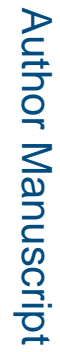

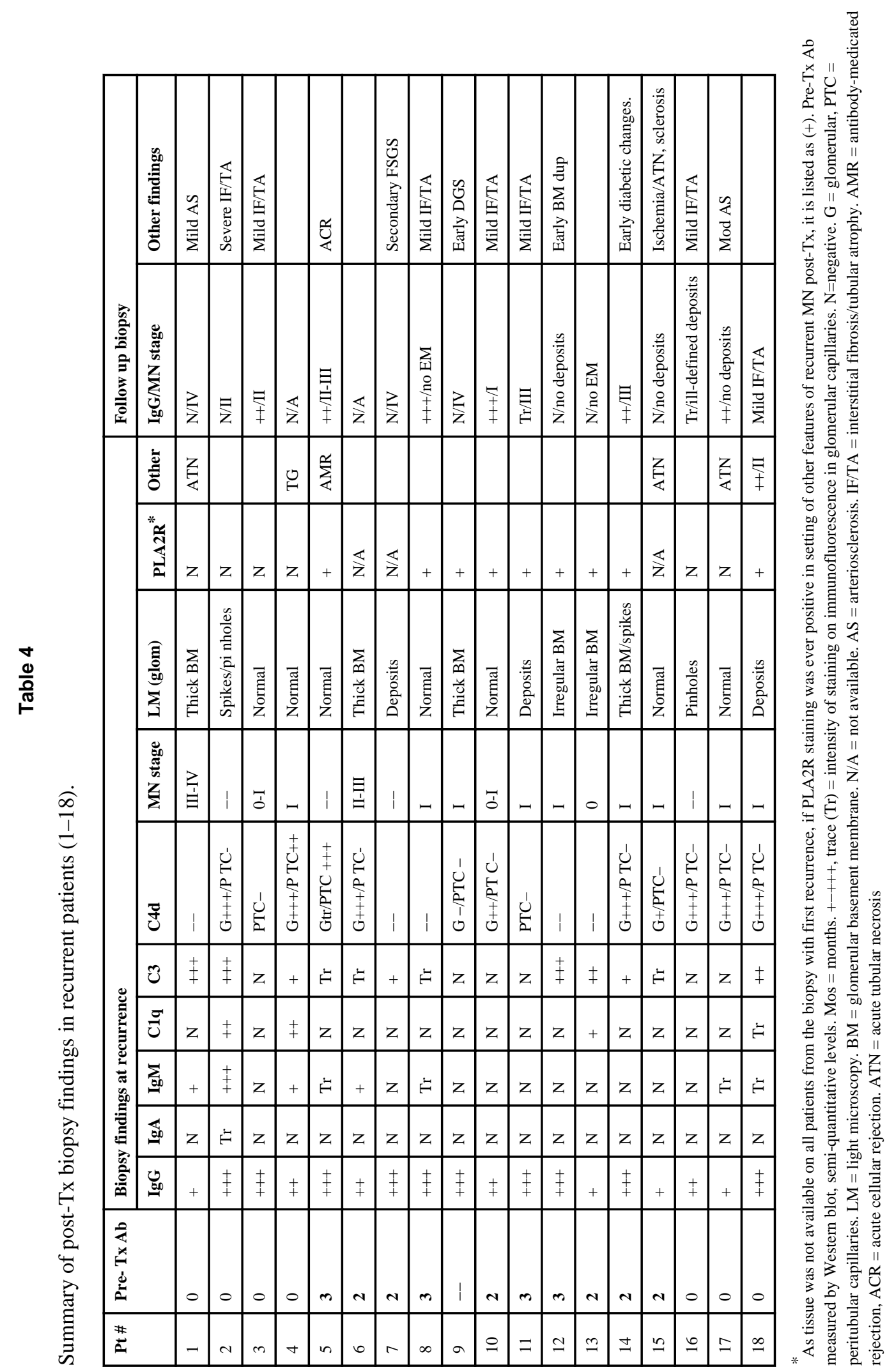

\&

들

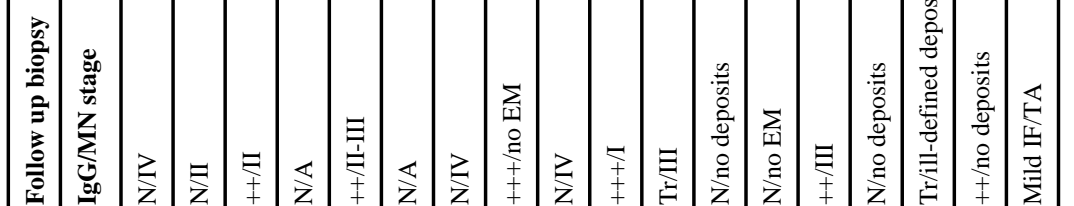

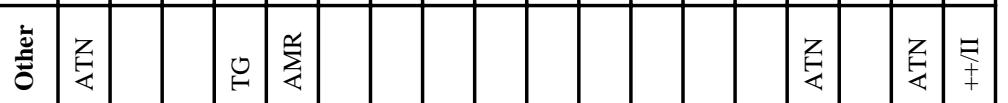

竎

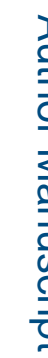

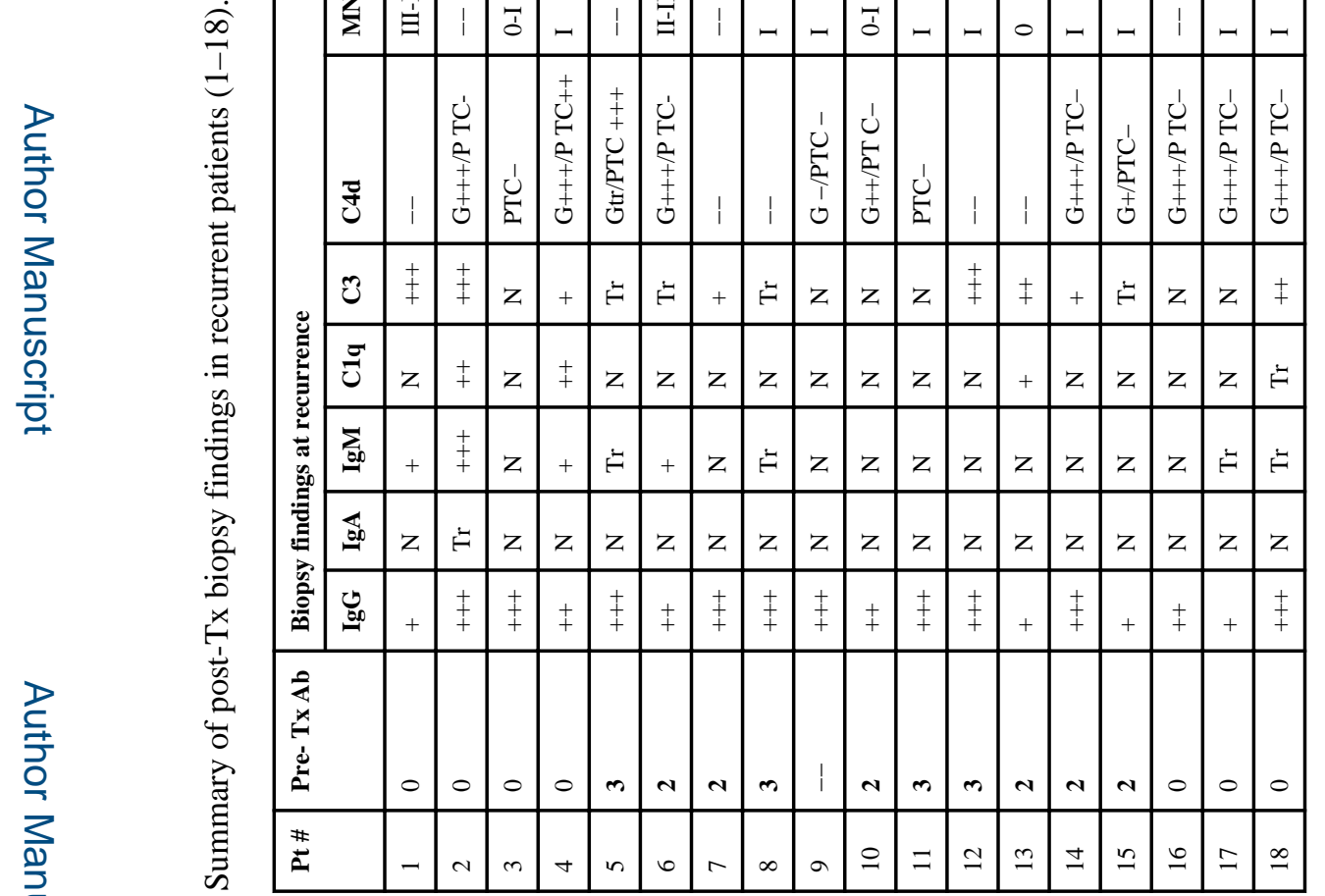

范

Am J Transplant. Author manuscript; available in PMC 2015 June 18. 